\title{
Video Article \\ Isolation of Translating Ribosomes Containing Peptidyl-tRNAs for Functional and Structural Analyses
}

\author{
Nitin Shirole ${ }^{1}$, Sreeram Balasubramanian ${ }^{1}$, Charles Yanofsky ${ }^{2}$, Luis Cruz-Vera ${ }^{1}$ \\ ${ }^{1}$ Department of Biological Sciences, University of Alabama Huntsville \\ ${ }^{2}$ Department of Biology, Stanford University \\ Correspondence to: Luis Cruz-Vera at Irc0002@uah.edu
}

URL: https://www.jove.com/video/2498

DOI: doi: $10.3791 / 2498$

Keywords: Molecular Biology, Issue 48, Ribosome stalling, ribosome isolation, peptidyl-tRNA, in vitro translation, RNA chemical modification, puromycin, antibiotics.

Date Published: 2/25/2011

Citation: Shirole, N., Balasubramanian, S., Yanofsky, C., Cruz-Vera, L. Isolation of Translating Ribosomes Containing Peptidyl-tRNAs for Functional and Structural Analyses. J. Vis. Exp. (48), e2498, doi:10.3791/2498 (2011).

\section{Abstract}

Recently, structural and biochemical studies have detailed many of the molecular events that occur in the ribosome during inhibition of protein synthesis by antibiotics and during nascent polypeptide synthesis. Some of these antibiotics, and regulatory nascent polypeptides mostly in the form of peptidyl-tRNAs, inhibit either peptide bond formation or translation termination ${ }^{1-7}$. These inhibitory events can stop the movement of the ribosome, a phenomenon termed "translational arrest". Translation arrest induced by either an antibiotic or a nascent polypeptide has been shown to regulate the expression of genes involved in diverse cellular functions such as cell growth, antibiotic resistance, protein translocation and cell metabolism ${ }^{8-13}$. Knowledge of how antibiotics and regulatory nascent polypeptides alter ribosome function is essential if we are to understand the complete role of the ribosome in translation, in every organism.

Here, we describe a simple methodology that can be used to purify, exclusively, for analysis, those ribosomes translating a specific mRNA and containing a specific peptidyl-tRNA ${ }^{14}$. This procedure is based on selective isolation of translating ribosomes bound to a biotin-labeled mRNA. These translational complexes are separated from other ribosomes in the same mixture, using streptavidin paramagnetic beads (SMB) and a magnetic field (MF). Biotin-labeled mRNAs are synthesized by run-off transcription assays using as templates PCR-generated DNA fragments that contain T7 transcriptional promoters. T7 RNA polymerase incorporates biotin-16-UMP from biotin-UTP; under our conditions approximately ten biotin-16-UMP molecules are incorporated in a $600 \mathrm{nt}$ mRNA with a 25\% UMP content. These biotin-labeled mRNAs are then isolated, and used in in vitro translation assays performed with release factor 2 (RF2)-depleted cell-free extracts obtained from Escherichia coli strains containing wild type or mutant ribosomes. Ribosomes translating the biotin-labeled mRNA sequences are stalled at the stop codon region, due to the absence of the RF2 protein, which normally accomplishes translation termination. Stalled ribosomes containing the newly synthesized peptidyl-tRNA are isolated and removed from the translation reactions using SMB and an MF. These beads only bind biotincontaining messages

The isolated, translational complexes, can be used to analyze the structural and functional features of wild type or mutant ribosomal components, or peptidyl-tRNA sequences, as well as determining ribosome interaction with antibiotics or other molecular factors $1,14-16$. To examine the function of these isolated ribosome complexes, peptidyl-transferase assays can be performed in the presence of the antibiotic puromycin ${ }^{1}$. To study structural changes in translational complexes, well established procedures can be used, such as i) crosslinking to specific amino acids $^{14}$ and/or ii) alkylation protection assays ${ }^{1,14,17}$.

\section{Video Link}

The video component of this article can be found at https://www.jove.com/video/2498/

Protocol

\section{Cell Free Extract Preparation.}

1. Two grams of a dry Escherichia coli bacterial pellet obtained from mid-log phase cultures are washed, twice, with half liter of buffer A containing $10 \mathrm{mM}$ Tris-acetate, $\mathrm{pH} 8.0,14 \mathrm{mM}$ magnesium acetate, $60 \mathrm{mM}$ potassium acetate, and $50 \mu \mathrm{g} / \mathrm{mL}$ phenylmethanesulphonylfluoride (PMSF) by centrifugation at $5000 \mathrm{Xg}$ for $5 \mathrm{~min}$ at $4^{\circ} \mathrm{C}$. After washing, the bacterial pellet is resuspended in $40 \mathrm{~mL}$ of buffer $\mathrm{A}$.

2. The bacterial cells are disrupted using a French Press, applying 6000 psi pressure. This pressure corresponds to 600 units using a one-inch piston. The disrupted suspension is collected in a clean glass tube $(50 \mathrm{~mL})$. 
3. The disrupted suspension is treated with $1 \mathrm{mM}$ dithiotreitol (DTT) and is centrifuged at $30,000 \times \mathrm{g}$ for 30 min. The centrifugation procedure is repeated, using the resulting supernatant. The final supernatant is dispensed $(1 \mathrm{~mL})$ into microtubes. Finally, the aliquots are frozen using a dry ice-ethanol mixture or liquid nitrogen, and are stored at $-60^{\circ} \mathrm{C}$ or $-80^{\circ} \mathrm{C}$.

\section{Preparation of Cell Free Extracts Depleted of RF2.}

1. $4.5 \mathrm{~mL}$ of protein A sepharose 4B slurry beads are mixed with $5 \mathrm{~mL}$ of an anti-RF2 anti-serum using a rotating wheel at room temperature for one hour. The mixture is centrifuged at $2500 \mathrm{xg}$ to separate the beads from the antiserum. Upon discarding the supernatant, these beads containing the anti-RF2 antibodies (anti-RF2 beads) are later washed by resuspension in $1 \mathrm{~mL}$ of buffer B containing $35 \mathrm{mM}$ Tris-acetate $\mathrm{pH} 7.8,10 \mathrm{mM}$ magnesium acetate, $30 \mathrm{mM}$ ammonium acetate, $60 \mathrm{mM}$ potassium glutamate and $5 \mathrm{\mu g} / \mathrm{mL}$ of leupeptin proteinase inhibitor. The anti-RF2 beads are then separated from buffer B by centrifugation using the same conditions indicated above. The washing procedure is repeated twice.

2. One $\mathrm{mL}$ of the cell-free extract is mixed with $150 \mu \mathrm{L}$ of anti-RF2 beads using a rotating wheel, at $4^{\circ} \mathrm{C}$, for two hours. The mixture is centrifuged at $10,000 \times \mathrm{g}$ to separate the cell-free extract from the beads. The supernatant is removed and treated again with another 150 $\mu \mathrm{L}$ of anti-RF2 beads. This procedure is repeated once more with the resulting cell-free extract solution. The final cell-free extract solution is dispensed $(100 \mu \mathrm{L})$ into microtubes. The aliquots are frozen using a dry ice-ethanol mixture or liquid nitrogen, and are stored at $-60^{\circ} \mathrm{C}$ or $-80^{\circ} \mathrm{C}$.

\section{Preparation of a DNA Template.}

1. Prepare a $1 \mathrm{~mL}$ PCR-reaction by mixing 600 femtomoles of the plasmid template containing the sequences to be translated (Fig 1 ), with 0.4 nanomoles of each of the oligodeoxynucleotides indicated in Fig 1, 0.2 micromoles of each dNTP and $50 \mathrm{U}$ of Taq-DNA polymerase in the buffer supplied by Stratagene Co. Perform the amplification reaction under the follow conditions: $94^{\circ} \mathrm{C}$ for 2 min, $\left(94^{\circ} \mathrm{C}\right.$ for $30 \mathrm{~s}, 55^{\circ} \mathrm{C}$ for 30 $\mathrm{s}, 72^{\circ} \mathrm{C}$ for $1 \mathrm{~min}$; for $30 \mathrm{cycles}$ ) and $72^{\circ} \mathrm{C}$ for $12 \mathrm{~min}$.

2. Purify the PCR-products by precipitating the DNA by adding $1 / 10$ volume of $3 \mathrm{M}$ sodium acetate, $\mathrm{pH} 5.2$, and 2 volumes of ice-cold ethanol. Repeat the precipitation procedure once more. Resuspend the DNA in $100 \mu \mathrm{L}$ of diethyl-pyrocarbonate (DEPC) treated-water. Typically, this procedure yields $100 \mu \mathrm{g}$ of a $600 \mathrm{bp}$ DNA product.

3. Verify the integrity of the PCR products by electrophoresis on agarose gels.

\section{Preparation of Biotin Labeled mRNA.}

1. Prepare a $100 \mu \mathrm{L}$ in vitro transcription reaction in DEPC treated water by mixing $5 \mu \mathrm{g}$ of the PCR-generated DNA fragment with 0.5 micromoles of ATP, CTP, GTP, 0.3 micromoles of UTP, 50 nanomoles of biotin-16-UTP, and $10 \mu \mathrm{L}$ of T7 enzyme mix in the buffer supplied by Promega Co. Incubate the reaction mixture at $37^{\circ} \mathrm{C}$ for 3 hours.

To quantify the amount of mRNA obtained, the DNA template should be eliminated by adding RNase-free DNase. Incubate the reaction at $37^{\circ} \mathrm{C}$ for $10 \mathrm{~min}$.

2. Purify the mRNA products by precipitating the RNA by adding $1 / 10$ volume of $3 \mathrm{M}$ sodium acetate, $\mathrm{pH} 5.2$, and 2 volumes of cold ethanol. Repeat the precipitation procedure once more. Resuspend the mRNA in $100 \mu \mathrm{L}$ of DEPC treated-water. Usually, this procedure yields between 1-2 mg of a $600 \mathrm{nt}$ biotin labeled mRNA product.

3. Verify the integrity of the biotin labeled mRNA products by electrophoresis on agarose gels.

\section{Isolation of Translating Ribosomes Containing a Peptidyl-tRNA.}

1. Prepare $500 \mu \mathrm{L}$ of an in vitro translation reaction mixture in DEPC treated water by mixing 10-15 $\mu \mathrm{g}$ of biotin-labeled mRNA with 75 nanomoles of each of the nineteen amino acids -all except the amino acid that will be replaced by a radioactive amino acid, $50 \mu \mathrm{Ci}$ of a radioactive amino acid (37MBq), and 20-50 $\mathrm{LL}$ of RF2-depleted cell-free extract, in a buffered reaction mixture containing $40 \mathrm{mM}$ Tris-acetate, $\mathrm{pH}$ 8.0, $10 \mathrm{mM}$ magnesium acetate, $175 \mathrm{mM}$ potassium acetate, $10 \mathrm{mM}$ ammonium acetate, $2 \mathrm{mM}$ DTT, $2 \mathrm{mM}$ ATP, $0.5 \mathrm{mM}$ GTP, $30 \mathrm{mM}$ phosphoenolpyruvate (PEP), $0.3 \mathrm{U} / \mathrm{mL}$ pyruvate kinase (PK), 3.5\% polyethylene glycol $8000,1 \mathrm{mM}$ spermidine, $20 \mu \mathrm{g} / \mathrm{mL}$ folinic acid, and $250 \mu \mathrm{g} / \mathrm{mL}$ tRNA from $E$. coli. Incubate the reaction mixture at $37^{\circ} \mathrm{C}$ for 10 minutes.

The order of addition of the reaction components is very important. The cell-free extract must be mixed first with the buffer solution containing the amino acids and the final mixture incubated for $5 \mathrm{~min}$ at room temperature to allow the activation of the ribosomes. Later, the biotinlabeled mRNAs are added. For structural analyses using chemical modification procedures, the addition of a radioactive amino acid is not required.

2. Add to the translation reaction mixture $-3 \mathrm{~mL}$ of streptavidin paramagnetic beads (SMB) suspended in buffer $\mathrm{C}$ containing $35 \mathrm{mM}$ Trisacetate, $\mathrm{pH}$ 8.0, $10 \mathrm{mM}$ magnesium acetate, $175 \mathrm{mM}$ potassium acetate, $10 \mathrm{mM}$ ammonium acetate and $1 \mathrm{mM}$ DTT. Incubate the new suspension at room temperature for $10 \mathrm{~min}$.

3. Separate the SMB from the mixture by applying a magnetic field (MF) using magnetic separation stands.

4. Resuspend the SMB in buffer $C$ and separate the beads again using the MF. Repeat this washing procedure twice. Resuspend the beads in $500 \mu \mathrm{L}$ of buffer $\mathrm{C}$, store the suspension on ice, and perform the next procedure immediately.

\section{Analysis of the Isolated Ribosomes Containing the Peptidyl-tRNA.}

\section{For peptidyl-tRNA}

1. Mix $10 \mu \mathrm{L}$ of the SMB (suspended in buffer $\mathrm{C}$ ) with $10 \mu \mathrm{L}$ of a loading buffer containing $50 \mathrm{mM}$ Tris- $\mathrm{HCl}, \mathrm{pH} 6.8,2.5 \%$ (v/v) glycerol, $4 \%$ sodium dodecyl sulfate, $2 \mathrm{mM}$ DTT and $0.2 \mathrm{mg} / \mathrm{mL}$ bromophenol blue. Resolve the components attached to the beads by running the samples in $10 \%$ Tris-tricine polyacrylamide gels. 
2. Dry the gels using a vacuum gel-dryer.

3. Verify the integrity and purification of the peptidyl-tRNA by exposing the dried gel to an X-ray film.

\section{For ribosomal RNA}

4. Add $190 \mu \mathrm{L}$ of $2 \mathrm{mM}$ ethylenediaminetetraacetate (EDTA) solution prepared with DEPC-treated water, and $200 \mu \mathrm{L}$ of phenol equilibrated with water, to $10 \mu \mathrm{L}$ of a bead suspension. Mix the suspension by vigorous vortexing and separate the inorganic phase from the organic phase by centrifugation at $10,000 \times \mathrm{g}$ for $3 \mathrm{~min}$ at room temperature. Collect the top water layer in a new microtube.

5. Precipitate the RNA from the water layer by adding $1 / 10$ volume of $3 \mathrm{M}$ sodium acetate, $\mathrm{pH} 5.2,1 \mu \mathrm{L}$ of $20 \mathrm{mg} / \mathrm{mL}$ of glycogen solution, and 2 volumes of ice-cold ethanol. Resuspend the RNA in $10 \mu \mathrm{L}$ of DEPC-treated water.

6. Verify the integrity of the ribosomal RNAs by electrophoresis on agarose gels.

Usually, $50 \mu \mathrm{L}$ of beads suspension yields $1 \mu \mathrm{g}$ of ribosomal RNA.

\section{Representative Results:}

Figure 2 presents the results of a series of analyses evaluating the quality and functionality of translating ribosomes isolated using the procedure outlined. The observation of a unique band resolved in polyacrylamide gels indicates the presence of polypeptides bound to the biotin-labeled mRNAs attached to the SMB (Figure 2A). The purification of ribosomal RNAs using this procedure establishes the presence of ribosomes bound to these biotin-labeled mRNAs, as well (Figure 2B). Addition of puromycin, an antibiotic that induces the peptidyl-transferase activity of the ribosome, results in cleavage of the nascent peptidyl-tRNAs ${ }^{1}$. This is observed as a shift in the migration pattern of the isolated polypeptide in polyacrylamide gels (Fig $2 \mathrm{C}$ ). Together, these data indicate that biotin-labeled mRNAs attached to the SMB contain functional ribosomes with peptidyl-tRNAs.

The isolation of translating ribosomes containing specific peptidyl-tRNAs permits the study of the effects of peptidyl-tRNAs, antibiotics, and other molecules, on ribosome function (Figure $3 \mathrm{~A}$ ), and on ribosome structure (Figure 3B). In the examples presented here the antibiotic sparsomycin and the amino acid tryptophan (Trp) inhibit the hydrolytic cleavage of the nascent tnaC-tRNA peptidyl-tRNA induced by RF2 in the isolated ribosomes (Figure $3 \mathrm{~A}$ ). The interaction of sparsomycin or Trp with the ribosome also induces structural changes in some nucleotides that constitute the $23 \mathrm{~S}$ rRNA of the translating ribosome (Fig 3B). In summary, the biological material obtained using the procedure described here are useful in obtaining additional understanding of the structural contacts involved in inhibition of ribosome function upon its interaction with various molecular factors.

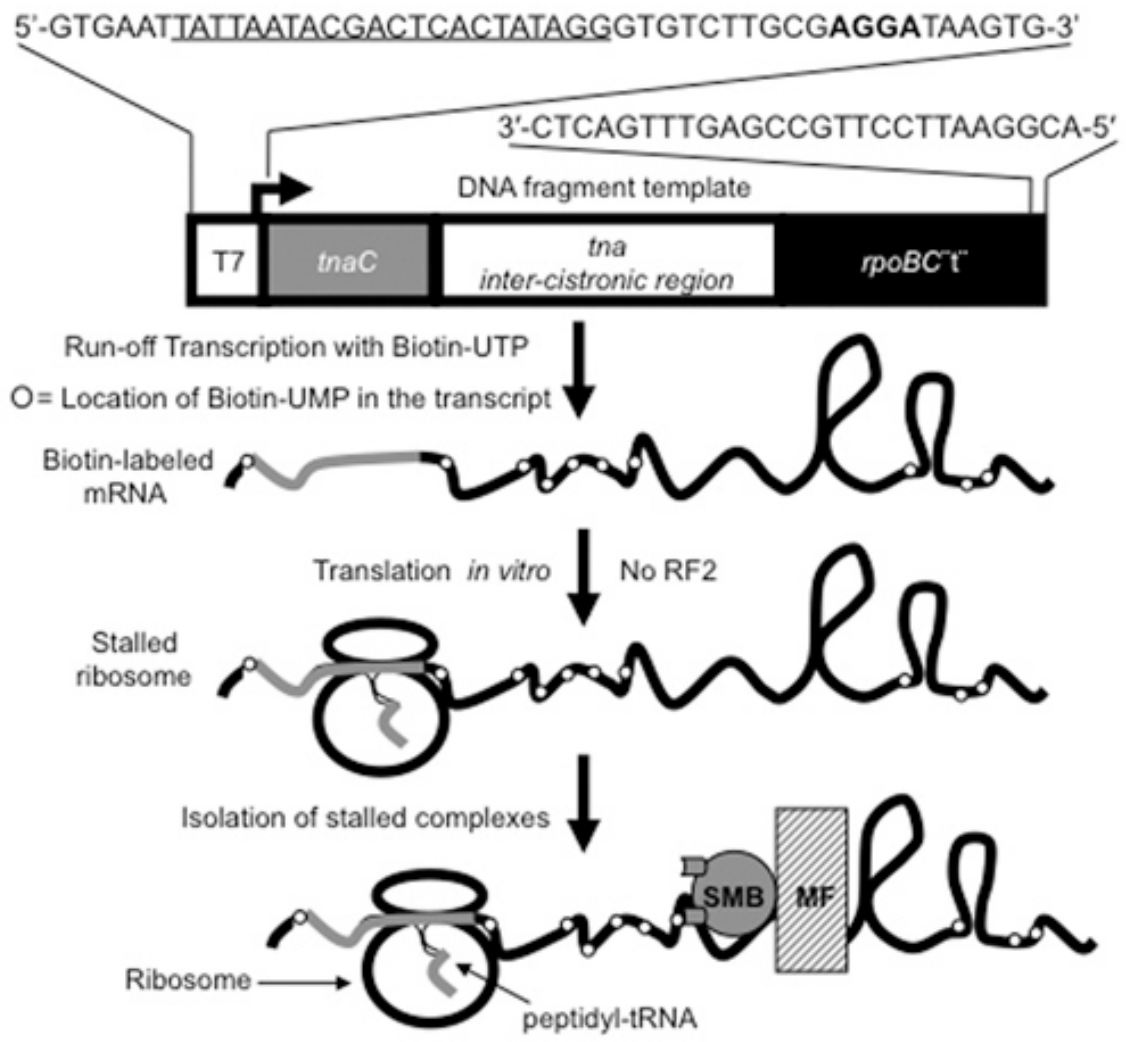

Figure 1. Procedure used to produce and purify translating ribosomes containing peptidyl-tRNAs. DNA fragments ca. 650 bp in length, containing the thaC gene and its adjacent region, shown in the figure, are used as templates in preparing mRNAs containing biotin, [(bio)UMP]mRNA. These DNA fragments are produced by PCR procedures using the oligodeoxynucleotides indicated at the top of the figure. Underlined letters mark the location of the T7 promoter encoded in the nucleotide primer. Bold letters indicate the Shine-Dalgarno sequence that is used in the translation of the tnaC mRNA sequences. The T7 promoter in the DNA fragment is recognized by T7 RNA polymerase which is used to transcribe (arrow) the tnaC sequence and the non-coding sequence downstream. Transcription is terminated when RNA polymerase reaches the $3^{\prime}$-end of the DNA fragment, after the $r p o B C$ terminator sequences ( $\left.r p o B C " t "\right)$. The stem-loop structure of the $r p o B C$ 
terminator protects the mRNA from the $3^{\prime}-5^{\prime}$ exoribonuclease activity present in the cell-free extracts used in the in vitro translation reactions. The isolated [(bio)UMP]mRNAs are used to generate stalled, translating ribosomes, using in vitro translation assays. The tnaC sequence in the [(bio)UMP]mRNA is translated by a ribosome which stalls when the last amino acid is incorporated, due to the absence of the Release Factor (RF2) from the reaction mixture. The ribosome-[(bio)UMP]mRNA complexes are isolated from the total reaction mixture using streptavidinmagnetic-beads (SMB) which bind the biotin-labeled nucleotides incorporated in the mRNA. The SMBs bound to the ribosome-[(bio)UMP]mRNA complexes are extracted from the total reaction mixture by using a magnetic field (MF).
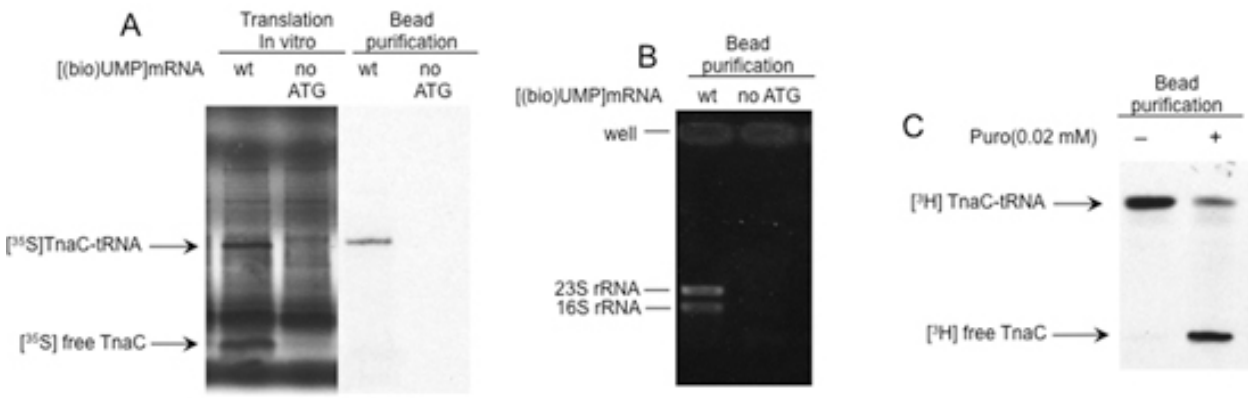

Figure 2. Structural and functional analyses of the isolated complexes. A) In vitro translation reactions were performed with [(bio)UMP]mRNAs in which the start codon of the tnaC gene was replaced by a stop codon. The final products were isolated using streptavidin beads, as is indicated in Fig 1. Reaction products and isolated molecules were then analyzed by electrophoresis on polyacrylamide gels. The tnaC-tRNA and tnaC peptide bands are marked. B) Total RNA was isolated from the stalled complexes using phenol extraction procedures. Each isolated RNA was resolved by electrophoresis in agarose gels. Ribosomal RNAs (rRNAs) are indicated. C) Isolated complexes containing tnaC-tRNAs were incubated with (+) or without (-) $0.02 \mathrm{mM}$ puromycin (Puro) at room temperature for $10 \mathrm{~min}$. The tnaC peptide were labeled during translation using [35S]-methionine $(\mathrm{A})$ or $[3 \mathrm{H}]-$ proline $(\mathrm{B})$.

A

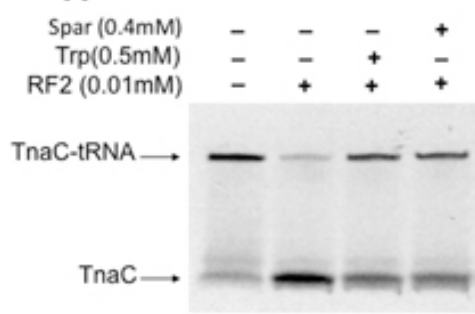

\section{B}

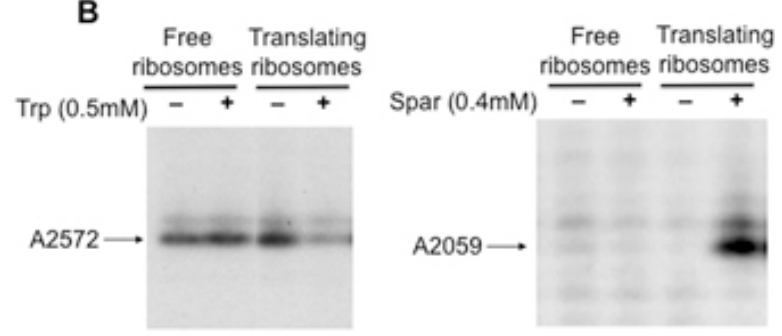

Figure 3. Structural and functional analyses of ribosomes containing thaC-tRNA that are bound to the antibiotic sparsomycin, or the amino acid tryptophan. A) Isolated complexes containing tnaC-tRNAs were incubated with (+) or without (-) sparsomycin (Spar) or tryptophan (Trp) at room temperature for $5 \mathrm{~min}$. Later, the mixtures were mixed with RF2 and incubated at $37^{\circ} \mathrm{C}$ for 20 min. B) Analysis of methylation changes in $23 \mathrm{~S}$ rRNA induced by molecules binding within the ribosome. Isolated complexes were pre-incubated with (+) or without (-) 2 mM Trp or Spar for $5 \mathrm{~min}$ at $37^{\circ} \mathrm{C}$. Then, an alkylation agent, dimethyl sulfate, was added and the mixtures incubated at room temperature for an additional 20 min. Total RNA was extracted and primer extension assays were performed with a [32P]-labeled oligodeoxynucleotide complementary to the nucleotides of 23S rRNA which are spaced 100 nucleotides downstream from the modified nucleotide. The final products of the extension assays were resolved by electrophoresis in polyacrylamide gels. The 23S rRNA nucleotides affected by the presence of Trp or Spar are indicated.

\section{Discussion}

This isolation procedure described in this report is highly reproducible. Unfortunately, the presence of short peptidyl-tRNAs produced from the same translated sequences cannot be conveniently avoided; such peptidyl-tRNAs may correspond to $15-20 \%$ of the total isolated material (Figure 2C). These contaminants may increase in concentration when higher concentrations of biotin-labeled mRNA have been used or when the cell-free extracts used are old or have been re-used several times. Therefore, it is very important to control the quality and concentration of the components of the in vitro translation reactions. Alternatively, commercial high efficiency reconstituted cell-free extracts are available that can be used for the same purposes (PURE system) ${ }^{18}$.

Using this method, biotin-16-UMP is randomly incorporated along the length of the target mRNA. There is a possibility that some ORFs containing uridine tracts may have incorporated this modified nucleotide in their sequences, affecting their translation. Variable relative concentrations of biotin-16-UTP/UTP have to be tested during synthesis of the mRNA in order to obtain the most efficient translation. Alternative methods of biotin labeling can be used, targeting the $5^{\prime}$-end, the most stable end of the mRNAs. (i) Biotin can be attached to the 5 '-end of the mRNA using 3'-NH2ATP (3'-amino, 3'-deoxyadenosine triphosphate) and T4 RNA ligase ${ }^{19}$. (ii) 5'-end biotin-labeled oligonucleotide can be attached to the $5^{\prime}$-end of the mRNA using T4 RNA ligase as well ${ }^{20}$. (iii) 3'-end biotin-labeled oligodeoxynucleotides which correspond to the complementary sequence at the 5 '-end of the mRNA could also be used to isolate the translating complexes. These biotin labeled oligodeoxynucleotides could be attached to the SMB prior to isolation. Later the SMB attached to the biotin-labeled oligodeoxynucleotides could be mixed with the translation reaction mixture to allow interaction with their complementary mRNA sequences. After isolation, the hybrid RNADNA region - and the region hybridizing between the biotin-labeled oligodeoxynucleotide and the mRNA sequence - could be degraded using 
RNAse $\mathrm{H}$, separating the stalled complexes from the streptavidin beads. This alternative method may allow the complexes to be employed in future structural analyses using higher resolution methods.

\section{Disclosures}

No conflicts of interest declared.

\section{Acknowledgements}

L.R.C.-V. wishes to dedicate this paper to the memory of Dr. Adriel D. Johnson, a wonderful Professor whose number one priority was always the education of students. We miss you, Adriel. We are grateful to Jacqueline Moreno for her help in performing the experiments described in this study. This study was supported by a grant provided to C.Y. from the National Science Foundation, MCB-0615390, and by start-up funds provided to L.R.C.-V. from the University of Alabama at Huntsville.

\section{References}

1. Cruz-Vera, L. R., Gong, M. \& Yanofsky, C. Changes produced by bound tryptophan in the ribosome peptidyl transferase center in response to tnaC, a nascent leader peptide. Proc. Natl. Acad. Sci. U. S. A 103, 3598-603 (2006).

2. Garza-Ramos, G., Xiong, L., Zhong, P. \& Mankin, A. Binding site of macrolide antibiotics on the ribosome: new resistance mutation identifies a specific interaction of ketolides with rRNA. J. Bacteriol 183, 6898-907 (2001).

3. Gaynor, M. \& Mankin, A. S. Macrolide antibiotics: binding site, mechanism of action, resistance. Curr. Top. Med. Chem 3, 949-61 (2003).

4. Polacek, N. \& Mankin, A. S. The ribosomal peptidyl transferase center: structure, function, evolution, inhibition. Crit. Rev. Biochem. Mol. Biol 40, 285-311 (2005).

5. Steitz, T. A. Structural insights into the functions of the large ribosomal subunit, a major antibiotic target. Keio J. Med 57 , 1-14 (2008).

6. Tenson, T. \& Mankin, A. Antibiotics and the ribosome. Mol. Microbiol 59, 1664-77 (2006).

7. Xiong, L., Korkhin, Y. \& Mankin, A. S. Binding site of the bridged macrolides in the Escherichia coli ribosome. Antimicrob Agents Chemother 49, 281-8 (2005).

8. Child, S. J., Miller, M. K. \& Geballe, A. P. Translational control by an upstream open reading frame in the HER-2/neu transcript. J. Biol. Chem 274, 24335-41 (1999).

9. Fang, P., Spevak, C. C., Wu, C. \& Sachs, M. S. A nascent polypeptide domain that can regulate translation elongation. Proc. Natl. Acad. Sci. U. S. A 101, 4059-64 (2004).

10. Janzen, D. M., Frolova, L. \& Geballe, A. P. Inhibition of translation termination mediated by an interaction of eukaryotic release factor 1 with a nascent peptidyl-tRNA. Mol. Cell. Biol 22, 8562-70 (2002).

11. Nakatogawa, H. \& Ito, K. The ribosomal exit tunnel functions as a discriminating gate. Cell 108, 629-36 (2002).

12. Onouchi, H. et al. Nascent peptide-mediated translation elongation arrest coupled with mRNA degradation in the CGS1 gene of Arabidopsis. Genes Dev 19, 1799-810 (2005).

13. Raney, A., Law, G. L., Mize, G. J. \& Morris, D. R. Regulated translation termination at the upstream open reading frame in sadenosylmethionine decarboxylase mRNA. J. Biol. Chem 277, 5988-94 (2002).

14. Cruz-Vera, L. R., Rajagopal, S., Squires, C. \& Yanofsky, C. Features of ribosome-peptidyl-tRNA interactions essential for tryptophan induction of tna operon expression. Mol. Cell 19, 333-43 (2005).

15. Cruz-Vera, L. R. \& Yanofsky, C. Conserved Residues Asp16 and Pro24 of tnaC-tRNAPro Participate in Tryptophan Induction of tna Operon Expression. J. Bacteriol 190, 4791-97 (2008).

16. Cruz-Vera, L. R., Yang, R. \& Yanofsky, C. Tryptophan inhibits Proteus vulgaris tnaC leader peptide elongation, activating tna operon expression. J Bacteriol 191, 7001-6 (2009).

17. Cruz-Vera, L. R., New, A., Squires, C. \& Yanofsky, C. Ribosomal features essential for tna operon induction: tryptophan binding at the peptidy transferase center. J. Bacteriol 189, 3140-6 (2007).

18. Shimizu, Y. et al. Cell-free translation reconstituted with purified components. Nat. Biotechnol 19, 751-5 (2001).

19. Kinoshita, Y., Nishigaki, K. \& Husimi, Y. Fluorescence-, isotope- or biotin-labeling of the 5 '-end of single-stranded DNA/RNA using T4 RNA ligase. Nucleic Acids Res 25, 3747-8 (1997).

20. Nishigaki, K., Taguchi, K., Kinoshita, Y., Aita, T. \& Husimi, Y. Y-ligation: an efficient method for ligating single-stranded DNAs and RNAs with T4 RNA ligase. Mol Divers 4, 187-90 (1998). 